\title{
BENEFICIO DE ALGUNAS ASOCIACIONES COMO MEDICACIÓN INTRACANAL
}

\author{
BENEFIT OF SOME ASSOCIATIONS AS INTRACANAL MEDICATION \\ Maria José Zumárraga Paredes ${ }^{1 a}$, Ana Carolina de Almeida Lima ${ }^{2 b}$, Thiago Resende da Silva ${ }^{1 a}$, Paulo \\ Henrique Weckwerth ${ }^{1 a}$, Guilherme Ferreira da Silva ${ }^{1 a}$
}

\section{RESUMEN}

Cuando es necesario completar el tratamiento endodóntico en más de una cita, se recomienda colocar medicación intraconducto con el fin de evitar el desarrollo demicroorganismos. Existen variasopciones, pero enmanos del endodoncista está saberqué usar en cada caso. De ahí nace la idea de una asociación entre los diferentes medicamentos. En vista de las propiedades antimicrobianas y de biocompatibilidad del hidróxido de calcio, se han buscado asociaciones de este con paramonoclorofenol, clorhexidina, antiinflamatorios y antibióticos. El paramonoclorofenol alcanforado, a pesar de que algunos estudios lo muestran como citotóxico, ayuda incrementando la acción del hidróxido decalcio, mientras quecuandosehicieron pastas de hidróxido decalcio yclorhexidina condiferentesconcentraciones, se observó eliminación microbiana pero esta acción no superó a la acción de la clorhexidina de forma separada. Entonces, se concluye que no hayuna potenciación en la combinación de estos medicamentos. El uso de analgésicos y antibióticos es una alternativa que ayuda en la desinfección yno interfiere enel pH. El principalobjetivode este trabajo esrealizaruna revisión de las posibles opcionesde asociación que se pueden presentar para medicaciones intracanal.

Palabras clave: hidróxido de calcio, clorhexidina, analgésicos, antibióticos. (Fuente: DeCS)

\section{ABSTRACT}

When it is necessary to complete a treatment in more than one appointment, it is recommended to place an intracanal medication in order toavoidthedevelopmentofmicroorganisms. Thereareseveraloptions; however, it dependsontheprofessionaltodecidewhichmedication is suitableforeachcase, hencethe idea of an associationbetweenthe different intracanalmedications. Inview of the antimicrobial, reducing, and anti-inflammatory properties of calcium hydroxide, an association with chlorhexidine, anti-inflammatory, antibiotics or others substances has been sought.

Once a paste of calcium hydroxide and chlorhexidine with different concentrations is prepared, the renewal of the tissue and microbial elimination was observed; however, this action did not outweigh the action of the chlorhexidine isolated, then we conclude that there is no potentiation in the combination of these drugs. On the other hand, some studies show that the chlorophenol camphorated has showed increasing the action of the calcium hydroxide. The use of analgesics, antibiotics are an alternative despite their likelihood of increasing the degree of resistance and allergies. This is why the objective of this study was to develop a bibliographic review of the possibilities of drug associations that can be used.

Keywords: Calcium Hydroxide, chlorhexidine, analgesics, antibiotics. (Source: MeSH NLM)

${ }^{1}$ Universidad do Sagrado Coração

a Reitoria de Investigación y Posgraduación, Bauru

bPregrado Odontologia, Bauru

Correspondencia:
Este es un artículo Open Access distribuido bajo la licencia Creative Commons Atribución-NoComercialCompartirlgual 4.0

(ㅇ)(○)

Guilherme Ferreira Da Silva

Dirección: Irmã Arminda, 10-50, Jardim Brasil, Bauru, São Paulo, Brasil.

Correo electrónico: gferreiras@hotmail.com

Teléfono: +55 1421077000

Citar como: Zumárraga - Torres MJ, Almeida - Lima AC, Resende da Silva T, Henrique Weckwerth P, Ferreira da Silva G. Beneficio de algunas asociaciones como medicación intracanal. KIRU. 2017;14(2):188-192. https://doi.org/10.24265/kiru.2017.v14n2.12 


\section{INTRODUCCIÓN}

El principal objetivo del tratamiento endodóntico de piezas dentales con necrosis pulpar y lesión periapical es la completa desinfección, no solo de la luz principal, sino también de todo el sistema de canales radiculares ${ }^{(1,2)}$. Esta limpieza es alcanzada por medio de la instrumentación, con auxilio de limas y soluciones irrigadoras. A pesar de que la literatura muestra que el tratamiento de estos casos puede ser realizado en una única sesión, en algunas situaciones, con necrosis prolongadas, puede ser necesaria la utilización de medicación intracanal para auxiliar en la completa eliminación de los microorganismos resistentes ${ }^{(1,2)}$.

Además, se sabe que las bacterias gram negativas, presentes en estos tipos de infección, liberan una endotoxina (lipopolisacáridos LPS) que actúa en la activación de citocinas inflamatorias y osteoclásticas, por lo que es necesaria la inactivación de LPS para el aumento del suceso de la terapia endodóntica(3,4).

Estudios revelan que el hidróxido de calcio utilizado como medicación intracanal entre sesiones inactiva los LPS bacterianos, es biocompatible y de efecto mineralizador, motivo por el cual es tradicionalmente utilizado como curativo de demora ${ }^{(5,6)}$.

La presente revisión fue organizada procurando describir las principales sustancias que pueden ser utilizadas como medicación intracanal en asociación con el hidróxido de calcio como paramonoclorofenol alcanforado, yodoformo, clorhexidina, antibióticos y antinflamatorios.

\section{Asociación del paramonoclorofenol alcanforado e hidróxido de calcio}

El paramonoclorofenol es un agente antibacteriano inespecífico que muestra irritabilidad en los tejidos. Su asociación con el alcanfor e hidróxido de calcio, ha sido una de las más efectivas durante mucho tiempo ${ }^{(7)}$. En 1997, Barbosa y cols. ${ }^{(8)}$ evaluaron la capacidad antimicrobiana de paramonoclorofenol alcanforado, clorhexixina al $0,12 \%$ e hidróxido de calcio. Realizaron un estudio clínico y de laboratorio, y en su estudio clínico tomaron muestras microbiológicas de pacientes con conductos instrumentados y medicados con paramonoclorofenol en su primera cita, para después dividirlos en tres grupos diferentes: paramonoclorofenol alcanforado, clorhexidina e hidróxido de calcio y hacer un análisis bacteriológico comparativo tomando muestras delos canales. En el estudio de laboratorio se usó pruebas de difusión de agar $\mathrm{BHI}$ para evaluar la actividad inhibitoria de los medicamentos contra las bacterias comúnmente encontradas en las infecciones endodónticas (Porphyromona endodontalis, Porphyromona gingivalis, Actinomices israelii, Fusobacterium nucleatum, Propionibacterium acnés, Actinomices naeslundii, Enterococus faecalis, Staphylococos aureus, Streptococos mutans, Pseudomonas aeroginosas). Los resultados de la evaluación clínica mostraron que todos los medicamentos eran eficaces para reducir o eliminar la microbiota endodóntica encontrada en esos canales; es decir, no hubo diferencias estadísticamente significativas entre los medicamentos probados, mientras que en la evaluación de laboratorio el paramonoclorofenol alcanforado mostró mayores zonas de inhibición bacteriana contra todas las cepas. Concluyeron que este medicamento es el de mejor elección.

En el mismo año de $1997^{(9)}$, se estudió la capacidad antimicrobiana de las siguientes asociaciones: paramonoclorofenol alcanforado (CPMC) con hidróxido de calcio; hidróxido de calcio con agua; hidróxido de calcio con glicerina; gel de clorhexidina $0,12 \%$; y en otro grupo, gel de metronidazol al $10 \%$, contra bacterias anaerobias estrictas y facultativas en agares BHI (Brain Heart Infusion). El resultado fue que todas las medicaciones testadas causaron inhibición, existiendo una mayor efectividad del hidróxido de calcio con CPMC y menor efectividad del hidróxido de calcio con agua destilada y glicerina.

La incidencia de hongos en las infecciones primarias de conductos radiculares ha sido reportada por varios estudios, existiendo también gran interés en cuanto al papel que desarrollan en infecciones secundarias o persistentes, asociadas con una terapia endodóntica fallida(10).

Siqueira y cols. ${ }^{(11)}$ evaluaron la efectividad para Candida albicans de cuatro medicamentos intracanales. Fueron utilizados dientes frescos de bovinos que se convirtieron en cilindros de dentina, los cuales fueron infectados con Candida albicans. Estos especímenes fueron divididos y expuestos a cuatro medicamentos diferentes: hidróxido de calcio con glicerina; hidróxido de calcio con digluconato de clorhexidina al 0,12\%; hidróxido de calcio con paramonoclorofenol alcanforado y glicerina; $y$ digluconato de clorhexidina al $0,12 \%$ con óxido de zinc. Los especímenes estuvieron en contacto con los medicamentos durante 1 hora, 2 días y 7 días. La viabilidad de $C$. albicans después de la exposición se evaluó mediante incubación de muestras en medio de cultivo para de este modo poder comparar la eficacia de los medicamentos en la desinfección de la dentina.

Los especímenes del grupo control dieron un cultivo positivo, mientras que el grupo tratado con hidróxido 
de calcio CPMC y pasta de glicerina y el grupo de pasta de clorhexidina con óxido de zinc desinfectaron la dentina y eliminaron por completo la $C$. albicans en los túbulos en una hora. En el grupo de hidróxido de calcio con glicerina se logró eficacia a los siete días. La pasta de hidróxido de calcio con clorhexidina fue ineficaz en la desinfección de la dentina incluso después de una semana de exposición a la medicación.

Concluyeron que entre los medicamentos probados, el hidróxido de calcio con paramonoclorofenol alcanforado y glicerina, y el digluconato de clorhexidina mezclado con óxido de zinc fueron los más efectivos.

\section{Hidróxido de calcio y yodoformo}

En un estudio de Souza Filho en 2008, la capacidad antimicrobiana y la variación de $\mathrm{pH}$ en hidróxido de calcio y clorhexidina $2 \%$ con asociaciones de yodoformo y óxido de zinc, como medicación intracanal, fue medida mediante cultivos de agar, mientras que el $\mathrm{pH}$ de las pastas se midió después de 5 minutos, 24 horas y 7 días con un $\mathrm{pH}$ metro. Se pudo observar que los halos de inhibición se presentaron en todos los medicamentos en el siguiente orden: $\mathrm{CHX}$ gel $2 \%$, seguido por $\mathrm{Ca}(\mathrm{OH})_{2+}$ $2 \% \mathrm{CHX}$ gel; $\mathrm{Ca}(\mathrm{OH})_{2}+2 \% \mathrm{CHX}$ gel + iodoformo; $\mathrm{Ca}(\mathrm{OH})+2 \% \mathrm{CHX}$ gel +óxido de zinc; $\mathrm{Ca}(\mathrm{OH}) 2+$ agua. Los microorganismos más resistentes fueron el E. faecalis, E. sanguis y Cándida albicans. En la medición de $\mathrm{pH}$ todas las pastas tuvieron una cifra $>$ 12 excepto la clorhexidina en gel que tuvo un $\mathrm{pH}=7$. En este estudio se cuestionó la desventaja de la forma más lenta de difusión del hidróxido de calcio en el agar con respecto a la clorhexidina, y la forma como el óxido de zinc y el yodoformo ayudan en la radiopacidad al tratarse de ciertos casos como apicoformación y apices abiertos ${ }^{(12)}$.

Estrela y cols en $2006^{(13)}$ concluyen en su estudio que el yodoformo no influencia en el potencial antimicrobiano del hidróxido de calcio. Realizaron una investigación teniendo como indicadores biológicos $S$. aureus, $E$. faecalis, $P$. aeruginosa, $B$. subtilis, C. albicans. Las sustancias ensayadas fueron: hidróxido de calcio más solución salina; hidróxido de calcio más yodoformo y solución salina; y yodoformo más solución salina. Para la prueba de difusión en Agar, se inocularon 18 placas de Petri con $20 \mathrm{ml}$ de agar $\mathrm{BHI}$ con las suspensiones microbianas. Se fabricaron cincuenta y cuatro cavidades en los platos de Agar y se llenaron con las sustancias ensayadas para medir los diámetros de inhibición microbiana. En la prueba de exposición directa, 162 puntas de papel absorbente estériles se sumergieron en las suspensiones experimentales durante 5 minutos, y se cubrieron con las pastas. En intervalos de 24, 48 y 72 horas, 18 puntas absorbentes se sumergieron en $10 \mathrm{ml}$ de Letheen Broth, seguido de incubación a $37^{\circ} \mathrm{C}$ durante $48 \mathrm{~h}$. El crecimiento microbiano se evaluó por turbidez del medio de cultivo, donde se transfirió un inóculo de 0,1 $\mathrm{ml}$ del caldo Letheen a $7 \mathrm{ml}$ de $\mathrm{BHI}$ y se incubó a 37 ${ }^{\circ} \mathrm{C}$ durante $48 \mathrm{~h}$. El crecimiento bacteriano se evaluó nuevamente por turbidez del medio de cultivo. En los resultados se muestra que no hubo significancia estadística entre las pastas que contienen hidróxido de calcio, mientras que la que contenía yodoformo mostro ineficacia.

\section{Hidróxido de calcio y clorhexidina}

Entre las sustancias que también se ha investigado para la asociación al hidróxido de calcio, esta la clorhexidina, que siendo incapaz de inactivar LPS y disolver tejidos, presenta sustantividad y espectro amplio de acción incluso contra hongos ${ }^{(5)}$.

Algunos autores mencionan que la clorhexidina presenta citotoxicidad para los tejidos. Faria y cols, en $2007^{(14)}$ evaluaron el grado de inflamación al inyectar clorhexidina al $0,5 \%$ y al $1 \%$ en patas de ratones y observaron el comportamiento de los fibroblastos. Encontraron que existió inflamación en las dos concentraciones, pero esta dependió del grado de concentración de clorhexidina. Donde hubo menos concentración, se generó menos lesión.

Silva y cols en $2009^{(15)}$ evaluaron la respuesta del tejido subcutáneo de 70 ratas frente a pastas de Calen (hidróxido de calcio) con digluconato de clorhexidina al $2 \%$ y Ultracal con clorhexidina al 0,4\%, siendo que este último presentó resultados semejantes al grupo control, es decir los resultados obtenidos fueron los mismos que al usar hidróxido de calcio puro. Demostraron que la pasta permitió el reparo del tejido, tomando en cuenta que en este estudio la reacción de ultracal más clorhexidina $2 \%$ fue insatisfactoria con respecto a la concentración de $0,4 \%$ de clorhexidina.

Existen investigaciones que tienen enfoque en la eliminación de ciertos microorganismos que son más difíciles de inactivar. Delgado y cols en 2010(6) estudiaron la eficacia del hidróxido de calcio $\mathrm{Ca}(\mathrm{OH})_{2}$ y gel de clorhexidina sobre la eliminación de $E$. faecalis. Utilizaron 60 dientes uniradiculares que fueron contaminados e inoculados com E. faecalis, para después dividirlos en grupos y colocar $\mathrm{Ca}(\mathrm{OH})_{2}$; gel de clorhexidina al 2\%; $\mathrm{Ca}(\mathrm{OH}) 2$ más gel de clorhexidina al $2 \%$; y solución salina ( $\mathrm{NaCl}$ al $0,9 \%$ ) como control negativo. Se analizaron las muestras obtenidas de los fragmentos dentinarios en cultivos 
de Agar y la viabilidad bacteriana usando microscopía de fluorescencia, con lo que pudieron concluir que tanto la clorhexidina como el $\mathrm{Ca}(\mathrm{OH})_{2}$ tienen efecto antimicrobiano. La clorhexidina aumentó su capacidad con respecto al $\mathrm{Ca}(\mathrm{OH})_{2}$ de forma aislada. La asociación de los dos compuestos, clorhexidina y $\mathrm{Ca}(\mathrm{OH})_{2}$ produjo un efecto similar al que se obtuvo con la clorhexidina sola.

El mismo autor, tres años más tarde ${ }^{(16)}$, investigó la eficacia del hidróxido de calcio y gel de clorhexidina para la eliminación de Candida albicans. Se usaron 65 dientes unirradiculares extraídos, 15 dientes sirvieron como control positivo y 15 dientes en cada uno de los otros tres grupos.

Las piezas dentales se trataron bajo procedimentos estandardizados para ser contaminadas con $C$. albicans. Posteriormente, se colocó en cada grupo respectivamente, hidróxido de calcio; gel de clorhexidina al $2 \%$; hidróxido de calcio más gel de clorhexidina al $2 \%$; y solución salina (cloruro de sodio al $0,9 \%$ ) como control positivo. Las muestras obtenidas a profundidades de 0-100 y 100-200 $\mu \mathrm{m}$ del sistema de conductos radiculares se analizaron para determinar la carga de $C$. albicans contando el número de unidades formadoras de colonias en Agar y el porcentaje viable usando microscopía de fluorescencia.

El uso de $\mathrm{Ca}(\mathrm{OH}) 2$ y $2 \%$ de clorhexidina en combinación y por separado redujo significativamente el número de $\mathrm{CFB}$ de $C$. albicans recuperados a profundidades de 0-100 $\mu \mathrm{m}$ en comparación con el control; sin embargo, no se observaron diferencias a una profundidad de 100-200 $\mu \mathrm{m}$ para cualquiera de los medicamentos antimicrobianos.

Concluyeron que el tratamiento con clorhexidina o clorhexidina en combinación con $\mathrm{Ca}(\mathrm{OH}) 2$ fue un antimicrobiano efectivo contra $C$. albicans cuando se usó como medicamento intracanal siendo más eficaz que el tratamiento solo con $\mathrm{Ca}(\mathrm{OH}) 2$.

\section{Hidróxido de calcio, antibióticos antiinflamatorios}

Valverde y cols, en $2017^{(17)}$, midieron la eficacia bacteriana in situ de pastas como TAP (pasta triple antibiótica), DAP (doble pasta antibiótica), $\mathrm{Ca}(\mathrm{OH}) 2$ sola o en combinación con clorhexidina o CTR (cetrimida), para ser usado como medicación intracanal en terapias regenerativas, con apices abiertos contaminados con E. faecalis. 138 raíces de dientes fueron tratadas de una forma estandarizada para ser contaminados e inoculadas con E. faecalis, y después colocadas las siguientes pastas: grupo 1:
TAP (metronidazol, ciprofloxacina, minociclina); grupo 2: DAP (ciprofloxacina y metronidazol); grupo 3: DBP ( $20 \%$ hidróxido de calcio, $30 \%$ carbonato de calcio, 50\% propilen glicol); grupo 4 : DBP+ 0,2\% clorhexidina; grupo 5: DBP + 0,2 \% de cetrimida; grupo 6: DBP + 0,2\% de clorhexidina+ 0,2\% CTR; grupo 7: irrigación con $20 \mathrm{ml}$ de $\mathrm{NaOCL} 2,5 \%$ y grupo 8: irrigación con $20 \mathrm{ml}$ de agua destilada.

Después de medir la inhibición de bacterias en Agar, $\mathrm{BHI}$, se determinó que a los 2 y 7 días no existió diferencia significativa entre los grupos experimentales, excepto para el $2,5 \%$ de $\mathrm{NaOCl}$ que mostró mayor reducción a los 2 días. Concluyeron que se debe comparar la eficacia y la biocompatibilidad en un escenario clínico para poder establecer un protocolo.

Otros estudios relatan que la adición de AINES y antibióticos a la pasta de hidróxido de calcio aumenta la actividad antimicrobiana contra $E$. faecalis y no interfiere en el pH de la pasta de hidróxido de calcio. Se realizó una investigación en la que utilizaron 30 dientes bovinos que se esterilizaron e inocularon con E. faecalis, para después del período de inducción del biofilm lavarlos con agua estéril e inocularlos en placas petri con la siguientes medicaciones: hidróxido de calcio con propilenglicol; hidróxido de calcio con propilenglicol y $5 \%$ de diclofenaco sódico; hidróxido de calcio con propilenglicol y $5 \%$ de ibuprofeno; hidróxido de calcio más propilenglicol y $5 \%$ de ciprofloxacino; y un grupo control positivo sin medicación. Los especímenes fueron analizados con microscopía confocal, tomando en cuenta que no hubo diferencia estadisticamente significativa entre las pastas de hidróxido de calcio con respecto al biovolumen y las pastas de hidróxido de calcio que contenian AINES y antibiótico tuvieron diferencia con el grupo control. Los valores del test de Ph estuvieron sobre 10 en todos los periodos analizados. El valor más alto se encontró en la pasta de ciprofloxacino y el más bajo en un intervalo de 24 horas fue con el diclofenaco ${ }^{(18)}$.

\section{CONCLUSIONES}

El hidróxido de calcio es considerado un padrón oro en la medicación intracanal. Todas las investigaciones buscan mejorar sus características, aun cuando este se utiliza como el principal curativo de demora en la mayoría de diagnósticos. Su asociación con el paramonoclorofenol y el alcanfor pese a ser una de las investigaciones más antiguas resulta ser muy acertada.

La clorhexidina es una bisguanida que posee numerosas características comprobadas, por lo que se puede pensar que se complementa con el 
hidróxido de calcio, pero realmente no hace diferencia al actuar sola o de forma acompañada. Su citotoxicidad está de acuerdo con su concentración. El uso de la clorhexidina se podría justificar como un complemento en la irrigación final de infecciones resistentes, mas no como medicación intracanal.

La unión de sustancias medicamentosas como analgésicos trae consigo la reducción de riesgo de resistencia antibiótica y alergias. No existe ninguna combinación medicamentosa que esté probada de forma clínica y laboratorial al mismo tiempo, lo que hace pensar que este aún es un tema de mucha controversia que podría seguirse investigando durante mucho tiempo.

\section{Referencias}

1. Paredes-Vieyra J, Javier $F$, Enriquez J, Javier $F$ Enriquez J. Success Rate of Single- versus Two-visit Root Canal Treatment of Teeth with Apical Periodontitis : A Randomized Controlled Trial. J Endod [Internet]. 2012; [Citado 12 julio 2017] 38(9):1164-9. Disponible http://dx.doi.org/10.1016/j.joen.2012.05.021

2 Wong $\mathrm{A}$, Zhang $\mathrm{C}$, Chu $\mathrm{CH}$. A systematic review of nonsurgical single-visit versus multiple-visit endodontic treatment. Clin Cosmet Investig Dent. 2014 May 8;6: 45-56.

3. Figini L, Lodi G, Gorni F. Single Versus Multiple Visits for Endodontic Treatment of Permanent Teeth: A Cochrane Systematic Review. 2008; 34(9):1041-7.

4. Vera J, Siqueira F, Ricucci D, Flores B, Loghin S, Fern N. One- versus Two-visit Endodontic Treatment of Teeth with Apical Periodontitis: A Histobacteriologic Study. 2012; 38(8).

5. Leonardo $M$, Leonardo $R$. Tratamento de Canais Radiculares. São Paulo: Artes Mèdicas; 2012. p. 3357.

6. Delgado RJR, Gasparoto TH, Sipert CR, Pinheiro CR, Moraes IG, Garcia RB, et al. Antimicrobial Effects of Calcium Hydroxide and Chlorhexidine on Enterococcus faecalis. J Endod. 2010;36(8):1389-93.

7. De Lima M. Endodontia. Da biologia á técnica. Sao Paulo:Santos; 2009.
8. Barbosa CA, Gonçalves RB, Siqueira JF, De Uzeda M. Evaluation of the antibacterial activities of calcium hydroxide, chlorhexidine, and camphorated paramonochlorophenol as intracanal medicament. A clinical and laboratory study. J Endod. 1997; 23(5): 297-300.

9. Siqueira JF, de Uzeda M. Intracanal medicaments: evaluation of the antibacterial effects of chlorhexidine, metronidazole, and calcium hydroxide associated with three vehicles. J Endod. 1997; 23(3):167-9.

10. Kumar Jay $R$, ohit sharma $M$ sharma. Presence of Candida albicans in Root Canals of Teeth with Apical Periodontitis and Evaluation of their Possible Role in Failure of Endodontic Treatment. J Int Oral Heal. 2015; 7(August 2014): 42-5.

11. Siqueira JF, Rôças IN, Lopes HP, Magalhães F a C, de Uzeda M. Elimination of Candida albicans infection of the radicular dentin by intracanal medications. J Endod. 2003; 29(8): 501-4.

12 Souza-filho FJ De, Soares ADJ, Paula B, Almeida F De. Antimicrobial Effect and $\mathrm{pH}$ of Chlorhexidine Gel and Calcium Hydroxide Alone and Associated with other Materials. 2008;19: 28-33.

13. Carlos E, Cintya E, Augusto H. Influence of iodoform on antimicrobial potential of calcium hidroxide Journal of applied oral science. 2006; (14)1: 33-37.

14. Faria G, Celes MRN, Rossi A De. Evaluation of Chlorhexidine Toxicity Injected in the Paw of Mice and Added to Cultured L929 Fibroblasts. 2007; 33(6): 71522.

15. Assed R, Assed S, Nelson-filho P, Assed L, Consolaro A. Subcutaneous Tissue Response of Isogenic Mice to Calcium Hydroxide-Based Pastes with Chlorhexidine. 2009; 20: 99-106.

16. Gasparoto $H$, Sipert $C R$, Pinheiro $C R$, Jacques $R$, Delgado $\mathrm{R}$, Duarte $\mathrm{H}$, et al. Antimicrobial activity of calcium hydroxide and chlorhexidine on intratubular Candida albicans. 2013; (January): 32-6.

17. Valverde ME, Baca P, Ceballos L, Fuentes MV, Ruizlinares M, Ferrer-luque CM. Antibacterial efficacy of several intracanal medicaments for endodontic therapy. Dent Mater J. 2017 May 31; 36(3): 319-324.

18. Freitas RP De, Greatti VR, Alcalde MP, Cavenago BC, Vivan RR, Antonio M, et al. Effect of the Association of Nonsteroidal Anti-inflammatory and Antibiotic Drugs on Antibiofilm Activity and $\mathrm{pH}$ of Calcium Hydroxide Pastes. 2017; 43(1): 131-4. 